\title{
Learning via a Social Media Enabled Tool - Do Learning Styles Make a Difference?
}

\author{
Vimala Balakrishnan, Member, IACSIT
}

\begin{abstract}
This paper investigated if students' varying learning styles affect the use of social media for learningbased on two learning styles, that is independent and collaborative. Questionnaires were used to gather the students' perceptions after using a social media enabled tool, which was specifically developed based on three key factors (i.e. Self, Effort and Function). A total of 48 students with Computer Science background were recruited to participate in the experiment. Path modeling analyses indicate the factors to predict $70 \%$ and $59 \%$ of usage among the independent and collaborative groups, respectively. Results show collaborative students to emphasize more on Function and Effort than Self, whereas Self and Effort had stronger impacts on the independent students than Function. Pair-wise comparisons revealed the differences between the learning styles to be significant for Self and Function, that is Self to be more important for independent students whereas Function was more important for the collaborative students. No significant differences were noted for Effort. The findings clearly indicate that students' learning styles play important roles in their learning activities, and hence academics should look into the possibilities of using different approaches in their teaching practices.
\end{abstract}

Index Terms-Social media, collaborative, independent, higher learning institutions.

\section{INTRODUCTION}

The use of the Web as an educational tool has been promoted by various academics, and is an integral part of higher education today. Recent years have also seen the adoption of social media tools by students and academics alike. The widespread use of such social media by the young generation is undeniable due to the benefits it brings to its users. In some aspects, the students are considered to be more technology savvy and in tune with the latest web technologies compared to the lecturers. Lecturers have now taken to using these tools for educational purposes in an effective attempt to reach out to their students, and to close the generational gap. For example, Moran et al. [1] found Facebook and YouTube to be widely used by faculty members in and outside classrooms for teaching purposes, such as to upload educational videos or learning materials for students to access them.

Qualitative study on the use of Twitter by 45 academics revealed that it is a useful tool for them to share information, resources, and other media about their classroom and students [2]. Microblogging is also another useful form of

Manuscript received July 14, 2014; revised September 12, 2014.

V. Balakrishnan is with the Faculty of Computer Science and Information Systems, University of Malaya, Kuala Lumpur, Malaysia (e-mail: vimala.balakrishnan@um.edu.my). communication to facilitate active interaction between students and their lecturers [3]. Outside the classroom, social network sites were also viewed favorably in e-learning courses, particularly as a vehicle for quick and easy communication amongst students and academics [4].

Educationists have also emphasized on students' learning styles, which refer to a person's preferred way of learning. Understanding students' learning styles are thus vital for educators, especially with the advent and wide use of social media tools. The current study aims to investigate if students' learning styles affect the use of social media for learning purposes. For this purpose, a prototype supporting some key functions of Facebook and YouTube were developed and tested. The results were then compared between the two groups of students. As will be presented later, overall results show different effects of the factors on the varying learning styles.

The remaining structure of the paper is as follows: the related works are presented in the next section followed by the research design. Next, the results are presented and discussed before the paper is concluded.

\section{RELATED WORK}

Many educational commentators have argued that social media offer great potential for supporting students' learning in higher education [5], [6]. Social media are currently being used to meet both formal and informal learning needs, and they also provide a source of user-developed learning content, offering a user experiences that encourage students to create and share new content while enabling communication about content and lessons. Social media can provide an environment that supports active learning for students as they are able to upload ideas and receive instantaneous feedback from peers and academics in an online group. Collaborative opportunities are abundant at sites such as Google Docs.

Literature suggests three types of learning styles, namely, independent, engagement and collaboration. They can be generally defined as follows:

1) Participant - students are eager to learn course content, enjoy learning, and take responsibility for their own learning,

2) Collaborative - students work well with others and enjoy cooperative learning and working in groups,

3) Independent - students are curious and confident learners and they prefer to work on their own in individual activities [7].

The current study focuses on two learning styles, that is, independent and collaborative.

Collaboration among students was deemed effective when handling complex and complicated assignments, and studies 
have proven collaborative learning to play a pivotal role for higher education students in critical thinking skills, social skills development, and fostering competitiveness[8], [9]. Collaborative learning also encourages critical thinking amongst students and retention of knowledge gained. Social media tools namely Facebook, YouTube and Twitter to name a few can foster robust collaborative efforts amongst students with the convenience of access to richer media such as video blogs. Students can learn by looking at the contributions of other students in the collaborative working space and by reflecting on their own contributions as well [10]. An exploratory study divided students into groups for a set of tasks and interactions took place via face-to-face meeting sessions in classrooms and via virtual meetings using groupware software [11]. The authors study concurred that social network elements were vital towards creative output during the collaboration processes.

\section{RESEARCH DESIGN}

The social media enabled tool used in the current study was developed based on three key factors, namely Self, Function and Effort. Self refers to elements related to enjoyment or fun, and also the skill and confidence one has in using a social media enabled tool. Self was particularly adapted from the Social Cognitive Theory. To accommodate this factor, utilities such as games, fun facts, quizzes etc. were included in the tool, as depicted in Fig. 1.

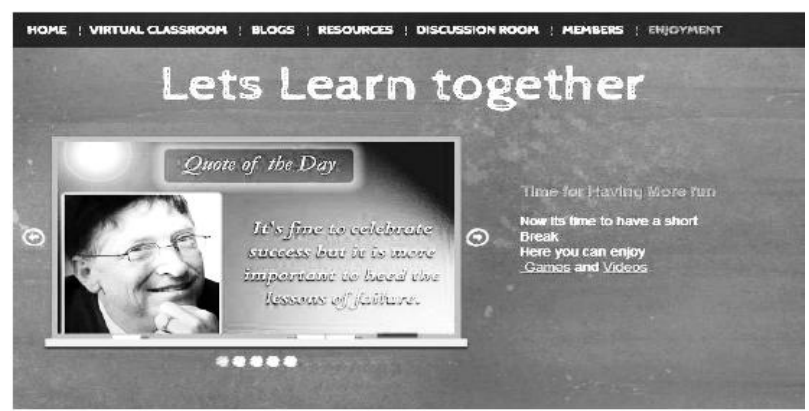

Fig. 1. Self.

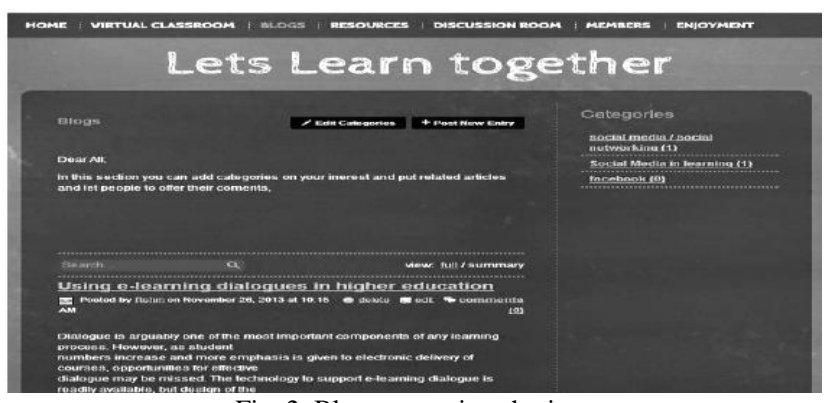

Fig. 2. Blog supporting sharing.

Function refers to elements that allow a user to communicate with one another. Additionally, it also supports collaboration with other users and enables one to share materials. Communication among members can be carried out in various ways, that is, real-time chatting, posting messages on wall (akin to Facebook), forum discussions or sending private messages to a user's inbox. Fig. 2 and Fig. 3 showsample screensfor a blog in which students can share their thoughts on academic issues, and a discussion room, respectively.

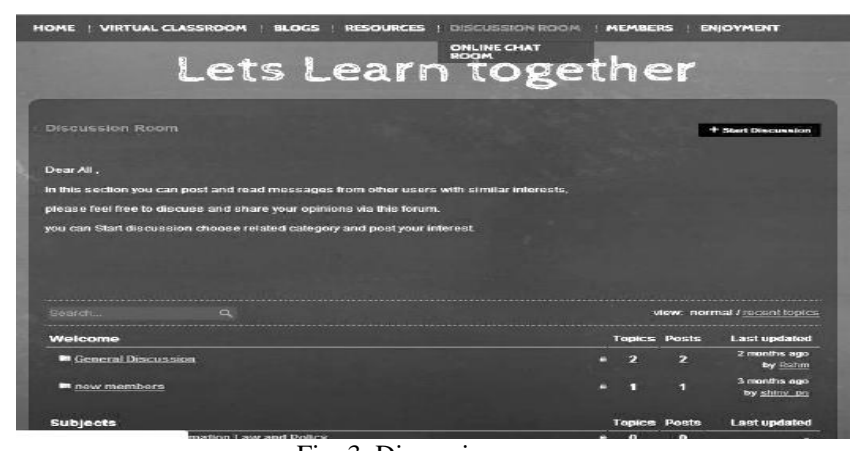

Fig. 3. Discussion room.

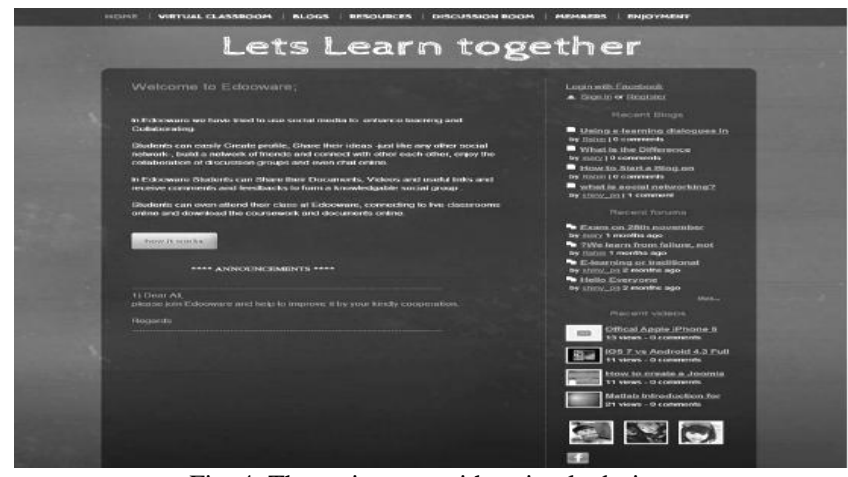

Fig. 4. The main page with a simple design.

Finally, Effort refers to the ease of using the tool, and also the ease of which one can learn to use the tool. The overall design of the tool was kept simple and users can navigate through the menus and tabs easily. Moreover, a help section is also available which provides basic explanation on the functions available. Fig. 4 illustrates the overall simple design.

\section{A. Experiment and Evaluation}

A total of 72 students with Computer Science background were recruited to evaluate the social media enabled tool. There were a total of 47 females and 25 males comprising of under-graduate students, ranging between the ages of $21-25$ years old. As for learning styles, 39 students claimed to be belong in the collaborative group whereas the remaining 33 in the independent group. A demo session was first conducted to introduce the tool and its functionalities to the students. They were then asked to use the tool for a period of two weeks before the questionnaire was administered.

The questionnaire consists of two parts, A and B. Part A focused on the demographic details such as age, gender, learning styles, years of using Internet etc. whereas Part B contained statements related to the key factors (i.e. Self, Function and Effort). All the statements were measured based on a five-point scale (1 - strongly disagree and 5 strongly agree).

\section{B. Data Analysis}

The descriptive statistics were used to analyze the demographic data. As for the path modeling, SmartPLS 2.0 was used to analyze the effects of learning styles on the use of the social media enabled tool. A multi-group analysis was carried out for collaborative and independent styles. Composite reliability (CR), Cronbach's alpha (CA) and average variance extraction (AVE) were checked to ensure the reliability and validity of the scales used, and both the models presented in this paper were found to be fit 
Bootstrapping was used to determine the significance of the paths [12].

\section{RESUlTS AND DISCUSSION}

Fig. 5 shows the path modeling analysis for the independent students. The overall prediction is approximately $70 \%$. Bootstrapping revealed the effects of Self and Effort to be significant, whilst Function had no significant effect on the tool usage.

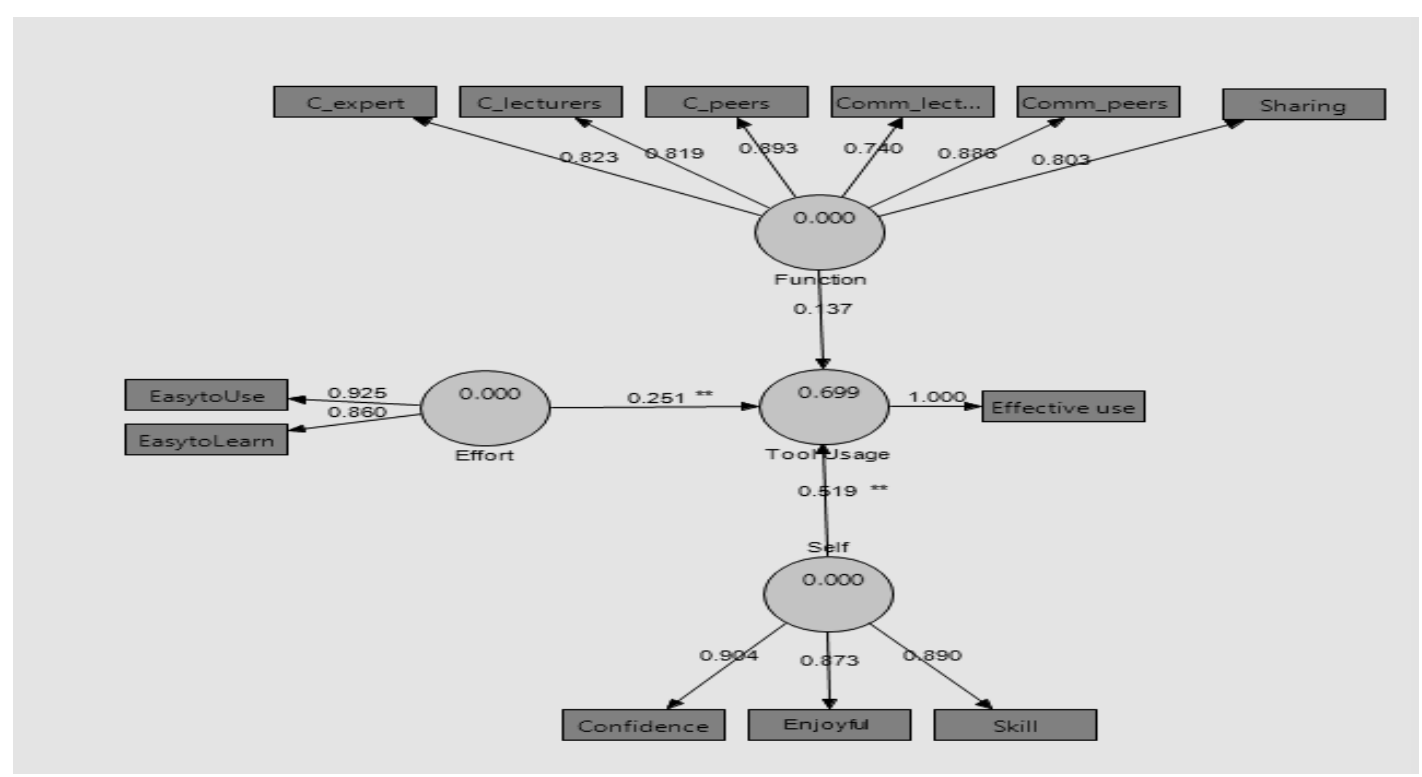

Fig. 5. Path modeling analysis for independent students.

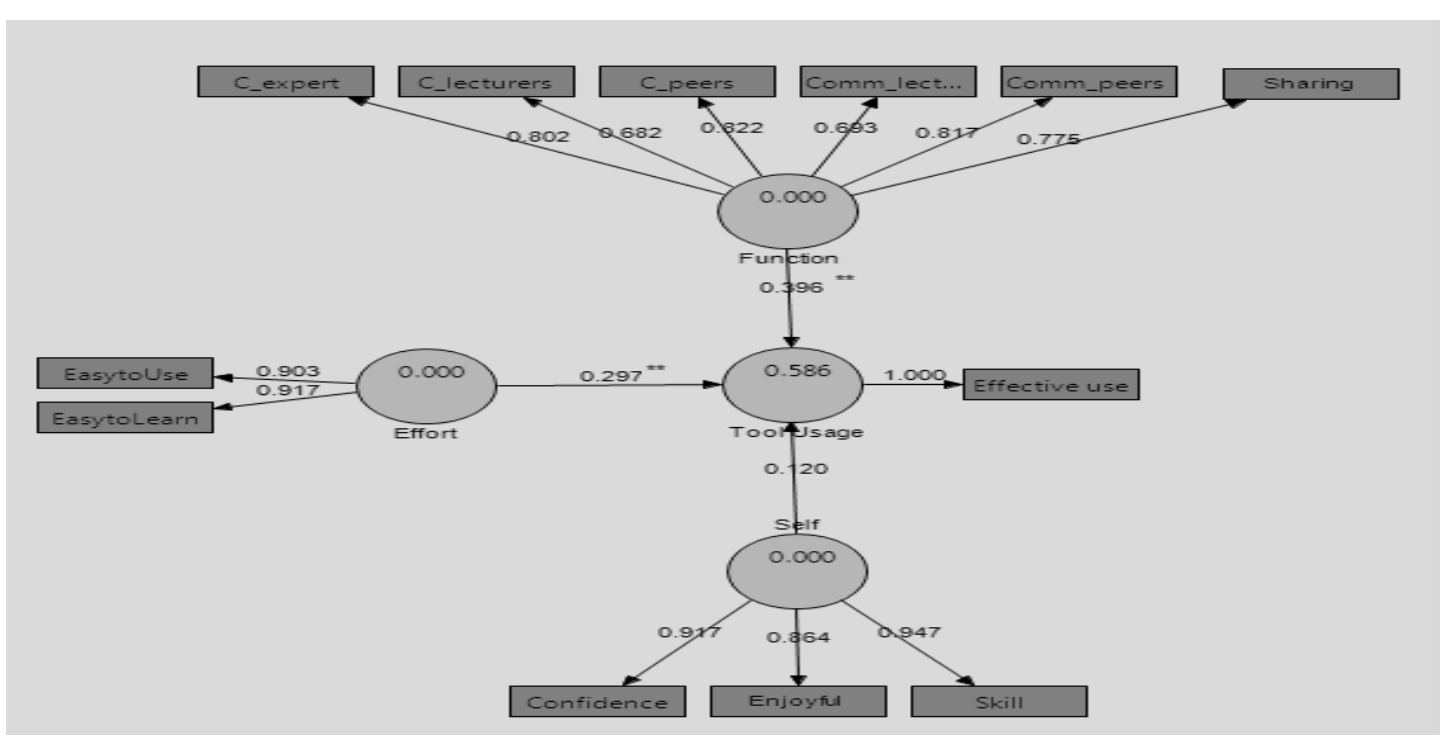

Fig. 6. Path modeling for collaborative student.

Looking at the path coefficients, it can be noted that Self had the strongest effect, followed by Effort on the tool usage for the independent students. This indicates that students' confidence and skill level play important roles in determining the use of technological tools in education. Moreover, it is also important to include fun features into teaching and learning, such as games or trivia quizzes.

On the other hand, the path modeling for the collaborative students revealed a lower predicting power, of approximately $59 \%$ as depicted in Fig. 6. Interestingly, Function was found to have the strongest effect on the tool usage, followed by Effort and Self. Further analysis revealed Function and Effort to be significant, whereas Self was insignificant. This clearly shows an opposite pattern when compared to the independent students.
Pair-wise comparisons were carried by comparing each of the factors between the two models. Table I shows the results of the comparisons.

TABLE I: COMPARISONS BETWEEN INDEPENDENT AND COLLABORATIVE STYLES

\begin{tabular}{l|l|l}
\hline \hline \multirow{2}{*}{ Self } & $t$-value & 3.488 \\
\cline { 2 - 3 } & $p$-value & $0.002 * *$ \\
\hline \multirow{2}{*}{ Function } & $t$-value & 5.608 \\
\cline { 2 - 3 } & $p$-value & $0.000 * *$ \\
\hline \multirow{2}{*}{ Effort } & $t$-value & 0.738 \\
\cline { 2 - 3 } & $p$-value & 0.224 \\
\hline
\end{tabular}

Significant differences were observed for Self $(p=0.002)$ and Function $(p<0.001)$. Self was found to have a significant 
stronger effect on tool usage for the independent students compared to the collaborative students. On the other hand, Function was found to have stronger effect on tool usage for the collaborative group than the independent group. No significant differences were noted for Effort.

As mentioned previously, Self refers to items that reflects one's confidence and skill in using the tool for learning purposes. Furthermore, it also encompasses using the tool for fun. Students with independent learning style prefer and are capable of carrying out most of the tasks on their own, probably with little guidance from the others. Therefore, they would probably have higher confidence level and not to mention more skills compared to the collaborative group. On the other hand, collaborative students prefer to work in a team or group to accomplish their tasks, hence Function plays a more important role in determining their tool usage. The Function in this study refers to the various communication and collaboration ways that are supported in the tool. These students might find these features to be beneficial as they are able to find and work with others in similar fields, hence they emphasized on the importance of Function more than the independent students. This is similar with studies that have reported the ability of social media in enhancing communication and collaboration, for instance, Wikis were found to be influential in group and collaborative works as they permit learners to collaborate in a mutual environment with the improvement of the work observable to all learners, and to the instructor, at any time [13], [14].

Finally, Effort was found to have significant effect on the tool usage, regardless of the learning styles. The tool is easy to use and students also found it interesting. The young generation in this era are quite technology savvy, and they would be familiar with most of the social media available, especially Facebook, YouTube and Twitter. Therefore, they probably had no issues in navigating through the tool. This probably explains why Effort was found to be significantly important for both the groups of students.

Overall, the study found that students with different learning styles emphasize on different factors with regards to using a social media enabled tool for learning. This suggests that academicians need to look into different approaches to cater for the students with different learning styles. Furthermore, higher learning institutions should also develop and encourage the use of social media enabled tool, such as the one developed in this study.

\section{CONCLUSION}

The study examined the effects of three factors, Self, Function and Effort on students intentions to use a social media enabled tool for learning, focusing on their learning styles. Questionnaires were administered and results indicate the students had no problems in using the tool considering the fact that the design was kept simple, and not to mention the students overall skill in using technological tools. However, independent students were found to emphasize more on Self than the collaborative students, whereas the reverse is true for Function.This clearly shows the need for academics to be able to plan and offer various teaching and learning approaches within a digital and social media context to cater to students' various learning styles. Acknowledgment

This study was supported by the University of Malaya (FL004-2012). Gratitude is also extended to Ms Shiva for developing the tool.

\section{REFERENCES}

[1] M. Moran, J. Seaman, and H. Tinti-Kane, "Teaching, learning, and sharing: How today's higher education faculty use social media," Babson Survey Research Group, 2011.

[2] G. Veletsianos, "Higher education scholars' participation and practices on Twitter," Journal of Computer Assisted Learning, vol. 28, no. 4, pp 336-349, 2012

[3] M. Ebner, C. Lienhardt, M. Rohs, and I. Meyer, "Microblogs in higher education - A chance to facilitate informal and process-oriented learning?" Computers \& Education, vol. 55, no. 1, pp. 92-100, 2010.

[4] K. P. Brady, L. B. Holcomb, and B. V. Smith, "The use of alternative social networking sites in higher educational settings: A case study of the e-learning benefits of Ning in education," Journal of Interactive Online Learning, vol. 9, no. 2, pp. 151-170, 2010.

[5] B. Lee and A. S. Sing, "Social media as an informal learning platform: case study on adult learning at SIM University, Singapore," ProcediaSocial and Behavioural Sciences, vol. 93, no. 21, 99 1158-1161, 2013.

[6] D. Y. Talug, "Lifelong learning through out today's occasions namely social media and online games," Procedia - Social and Behavioral Sciences, pp. 4431-4435, 2012.

[7] F. Umrani-Khan and S. Iyer, "ELAM: a model for acceptance and use of e-learning by teachers and Students," in Proc. the International Conference on e-Learning, p. 475, 2009.

[8] T. Castor, "Making student thinking visible by examining discussion during group testing," New Directions for Teaching and Learning, vol. 100, pp. 95-99, 2004.

[9] P. Galagan, "Slash, burn, and learn, T+D," vol. 63, no. 5, pp. 28-31, 2009.

[10] S. Minocha, "An empirically-grounded study on the effective use of social software in education," Education+ Training, vo. 51, no.5/6, 381-394, 2009.

[11] A. Gaggioli, E. Mazzoni, L. Milani, and G. Riva, "The creative link: Investigating the relationship between social network the creative link: Investigating the relationship between social network," Computers in Human Behaviour, 2013.

[12] J. F. Hair, C. M. Ringle, and M. Sarstedt, "PLS-SEM: Indeed a silver bullet," The Journal of Marketing Theory and Practice, vol. 19, no. 2, pp. 139-152, 2011.

[13] T. Miyazoe and T. Anderson, "Learning outcomes and students' perceptions of online writing: Simultaneous implementation of a forum, blog, and wiki in an EFL blended learning setting system," System, vol. 38, no. 2, pp. 185-199, 2010.

[14] R. W. Lundin, "Teaching with wikis: Toward a networked pedagogy," Computers and Composition, vol. 25, no. 4, pp. 432-448, 2008.

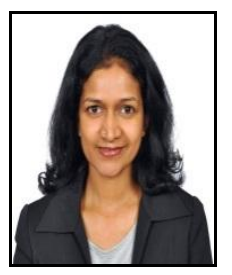

V. Balakrishnan received her $\mathrm{PhD}$ in the field of ergonomics in 2009 from Multimedia University, Malaysia. Both her master and bachelor degrees were from University of Science, Malaysia.

She is currently affiliated with the Faculty of Computer Science and Information Technology, University of Malaya as a senior lecturer. Most of her research works are in the field of data engineering, opinion mining, information retrieval and health informatics.

Dr. Balakrishnan is also a member of the Medical Research Support (Medicres) group, IACSIT and Global Science and Technology Forum. 